\title{
Beneficiamento local da produção extrativista e agroflorestal
}

\section{O caso da Cooperativa Agroextrativista de Xapuri - CAEX}

\author{
Fernando Michelotti \\ Pesquisador associado do NAEA
}

\section{Resumo}

O objetivo do artigo é analisar as dificuldades de consolidação econômica vivenciadas pela

Cooperativa Agroextrativista de Xapuri - CAEX ao longo da sua existência. A Cooperativa fundada em 1988 por seringueiros do município de Xapuri, no estado do Acre, é um exemplo das dificuldades de implantação de um projeto de beneficiamento local da produção agro-extrativista. A proposta de agregar valor à produção dos cooperados através do beneficiamento da castanha-do-brasil apresentou resultados econômicos bem abaixo do esperado. Grande parte das análises existentes sobre essa situação isolam alguns aspectos sócio-econômicos da Cooperativa e enxergam neles as causas exclusivas dos seus problemas. Nesse trabalho utilizaram-se ferramentas conceituais da economia evolucionária o que permitiu o reconhecimento de problemas estruturais na experiência.

\section{Palavras-Chave}

Amazônia - Cooperativismo Agricultura Familiar - Camponeses Extrativismo - Acre

\begin{abstract}
The main purpose of this paper is to elucidate the difficulties faced by Cooperativa Agroextrativista de Xapuri (Xapuri Agroextrativist Cooperative) to achieve its economical viability. Created in 1988 by the rubber tapers from Xapuri (Acre/Brazil), its case study provides an interesting example of an attempt to establish a local agro-extrativist production processing project. This project aimed to aggregate value by processing its members' Brazil nuts production. The economical return of this iniciative, however, turned out to be less than the expected. Most of the studies dealing with the evaluation of these poor economical results identified as the main causes isolated socioeconomical factors happening in the production and comercialization process. Using conceptual framework of the evolutionary economy, this study pursues the identification of others structural problems as the primary causes leading to this bad economical return.
\end{abstract}

\section{Keywords}

Amazon - Cooperativism - Peasants Extrativism - Acre - Formhousehold 


\section{Introdução}

Com a nova dimensão que assumiu a questão ambiental a partir da década de 80, a Amazônia tornou-se um símbolo mundial da necessidade de preservação da natureza. Criou-se um amplo consenso acerca da necessidade de valorização das práticas que menos impacto direto tivessem no meio ambiente. Esse consenso, no entanto, é aglutinador de uma gama variada de interesses q ue aparentemente se reuniram sob uma bandeira comum: preservar a floresta tropical (Costa, 1992).

Tal contexto deu uma maior visibilidade a determinados sujeitos sociais, identificados como portadores de práticas e saberes de uso sustentável da floresta. Ao mesmo tempo, contribuiu para a criação de novas modalidades fundiárias e políticas públicas voltadas para a valorização desses sujeitos. O exemplo das reservas extrativistas é bastante ilustrativo disso.

No entanto, ao par dos avanços na legitimação da posse da terra por esses sujeitos sociais, não se garantiram políticas econômicas que valorizassem suas atividades e a reprodução do seu modo de vida. Por isso, tornou-se fundamental a busca de alternativas para a melhoria econômica das suas formas de produção. Apesar das especificidades de cada uma das diversas categorias envolvidas, alguns pontos essenciais passaram a compor um projeto comum de desenvolvimento rural sustentável amazônico embasam-se em três componentes: o uso sustentável da floresta por meio de atividades extrativistas; a intensificação e/ou a diversificação da produção agropecuária nas áreas já alteradas, com ênfase nos cultivos perenes, principalmente mediante sistemas agroflorestais (SAF); a agregação de valor à produção por meio do beneficiamento local.

Apesar de crescentemente incentivado o projeto apresenta ainda muita incerteza, tanto sobre as reais possibilidades, quanto em relação aos caminhos que devem ser trilhados para a implementação bem sucedida. Mesmo assim, por toda a Amazônia, vários são os exemplos de iniciativas voltadas para a implantação de um ou mais de seus componentes. Em muitos desses exemplos, mesmo quando há um relativo sucesso nas experiências de manejo extrativista da floresta e de diversificação/intensificação da produção agroflorestal, o projeto esbarra em problemas na comercialização da produção e na capacidade de obter resultados econômicos favoráveis. 
Por isso, a agregação de valor aos produtos, através de unidades de beneficiamento agroindustrial locais tem sido bastante enfatizada. Não obstante, várias das experiências não têm conseguido resolver os problemas econômicos a que se propõem. Esse fato tem sido considerado por alguns analistas como sinais da inviabilidade do mencionado projeto de desenvolvimento rural sustentável amazônico. Não é essa a nossa opinião. Entendemos que essas análises, por vezes apressadas e embasadas em modelos teóricos inadequados, não têm permitido uma verificação mais penetrante dos reais problemas com que as experiências têm se defrontado. Conseqüentemente, tem-se avançado pouco na definição de soluções.

O objetivo desse trabalho é levantar elementos para a análise das dificuldades de consolidação de projetos de beneficiamento local da produção extrativista e agroflorestal. Para tanto, será apresentado o caso da Cooperativa Agroextrativista de Xapuri-CAEX. Pretende-se que a análise desse caso específico ilustre alguns elementos centrais para a consolidação dessa e de outras iniciativas correlatas. Não se pretende com isso, criar uma generalização de problemas e soluções, mas, ao contrário, reafirmar a especificidade de cada situação e a necessidade de serem encontradas formas próprias de superação de problemas. A identificação de uma problemática de fundo, comum a diversas experiências, pode, no entanto, contribuir para a compreensão das situações específicas em que elas se manifestam.

Nessa perspectiva, o trabalho busca reafirmar a importância de um projeto de desenvolvimento rural sustentável para a Amazônia, trazer à discussão alguns elementos críticos da situação atual que estão barrando uma tal possibilidade e, dessa maneira, contribuir para a sua superação.

\section{A Cooperativa Agroextrativista de Xapuri - CAEX}

Em Assembléia realizada a 30 de junho de 1988, foi fundada a Cooperativa Agroextrativista de Xapuri - CAEX por 34 seringueiros. De acordo com o Estatuto ali aprovado, os principais objetivos da CAEX referiam-se ao desenvolvimento econômico dos seus associados com base no aprimoramento de suas atividades extrativistas e agrícolas. Para isso, previam-se ações na comercialização, industrialização e beneficiamento da produção e na venda de mercadorias de consumo, bem como em atividades de aprimoramento técnico-profissional.

Logo de início, algumas prioridades foram estabelecidas como parte de uma estratégia de consolidação da Cooperativa. Chamam a atenção dois pontos principais: a busca de ampliação do número de sócios e a elevação do preço pago aos produtos extrativistas, sobretudo a borra- 
cha. Esses dois pontos eram complementares, pois os melhores preços pagos aos sócios poderiam atrair novos cooperados. Entretanto, esse maior preço só se sustentaria com ganhos de escala e melhores condições de negociação junto ao mercado a partir de um maior volume de produção, alcançado com a ampliação do quadro social.

Na reunião do Conselho de Administração de 04.10.89, afirmouse que a Cooperativa, apesar dos benefícios que vinha trazendo para os seringueiros, em função da pressão para o aumento dos preços da borracha, não estava conseguindo ampliar seu capital. Por isso, definiu-se como prioridade a ampliação do quadro social da CAEX (cf. Livro de Atas da CAEX - reunião do Conselho de Administração de 04.10.89). Como meta de crescimento, chegou-se a prever um quadro social de 200 cooperados até o final de 1989 (cf. STR de Xapuri, 1989).

Em relação à importância dada à questão dos preços pagos, Chico Mendes, em entrevista realizada em setembro de 1988, afirmou:

Criamos a primeira cooperativa agroextrativista em 30 de junho deste ano. Antes de sua fundação, os patrões pagavam Cz\$150,00 o quilo da borracha, depois de criada a cooperativa, com o objetivo de derrubá-la, passaram a pagar Cz\$230,00 o quilo, e nós conseguimos pagar Cz\$264,00. Três semanas depois chegaram a esse preço e nós passamos para Cz\$285,00. Quando acreditaram que pararíamos, nós passamos para $C z \$ 380,00$. (entrevista de Chico Mendes à revista do STR de Xapuri, CNS, CUT, 1989: 11).

A estratégia inicial adotada pela CAEX acarretou várias conquistas. O número de associados teve um crescimento inicial significativo, apesar de ficar abaixo da meta estipulada: a cooperativa chegou ao final de 1988 com 69 sócios e ao final de 1989 com 130 sócios. Esse rápido crescimento inicial, tanto do quadro social como do volume de produção comercializada, impôs algumas mudanças na forma de funcionamento da entidade, como a estruturação de uma sede própria e montagem de uma equipe permanente de trabalho na cidade.

Esse quadro reforçou alguns problemas, como o transporte da produção dos seringais até a cidade e do capital de giro para a compra dos produtos, que impediam o cumprimento das metas esperadas. A necessidade de ampliar o capital de giro ultrapassou a capacidade de captação por meio das cotas-partes integralizadas pelos novos sócios, e com isso a CAEX começou a buscar financiamentos externos (cf. STR de Xapuri, 1989).

Mesmo conseguindo aumentar sua captação externa, a partir de 1989, sobretudo após o assassinato de Chico Mendes, a continuidade do crescimento da Cooperativa e a manutenção de sua estratégia de 
elevação dos preços pagos aos produtos extrativistas esbarraram em certos limites. Isso fez com que duas novas metas passassem a ter uma posição central na estratégia da CAEX: a diversificação da produção nas colocações (espaço de funcionamento da unidade de produção), a médio prazo, para ampliar a renda das famílias, e a agregação de valor à produção extrativista, por meio de usinas de beneficiamento. A busca de recursos externos começou, então, a ser direcionada para isso.

Já em 1990, com financiamento externo, a CAEX inaugurou sua Usina de Beneficiamento de Castanha. Com isso, a Cooperativa passou a comprar regularmente não apenas borracha, mas também castanhado-brasil. Com a Usina, a CAEX deu um passo importante para a consolidação de sua estrutura na cidade de Xapuri, ampliando sua força tanto econômica, como política no município.

O aumento de sua força político-econômica foi bastante enfatizado pela diretoria e seus assessores no Relatório da Administração Geral, elaborado pela gestão 1989/1990. Comemorava-se o fato de a Cooperativa, desde sua inauguração, ter se tornado a principal reguladora de preços de borracha e castanha na região, forçando inclusive o aumento dos preços da concorrência, o que beneficiava não só os seus cooperados, mas também todos os seringueiros da localidade. Além disso, com a construção da Usina de Beneficiamento de Castanha, o mesmo relatório afirmava que a CAEX tinha passado a ser "a empresa do setor privado com maior número de empregados e maior geradora de tributos estaduais no município de Xapuri" (cf. CAEX, 1991).

Tabela 1 - Evolução anual do quadro social da CAEX entre 1988 e 2000.

\begin{tabular}{|c|c|c|c|c|c|c|c|c|c|c|c|c|c|c|c|}
\hline & $\begin{array}{l}\text { Início } \\
30.6 .88\end{array}$ & 1988 & 1989 & 1990 & 1991 & 1992 & 1993 & 1994 & 1995 & 1996 & 1997 & 1998 & 1999 & 2000 & $\begin{array}{l}\text { s/ data } \\
\text { regist }\end{array}$ \\
\hline Admitidos (A)34 & 35 & 61 & 40 & 8 & 17 & 55 & 15 & 23 & 28 & 9 & 5 & 15 & 75 & 6 & \\
\hline Desligados (B) & 0 & 0 & 0 & 4 & 8 & 7 & 8 & 8 & 6 & 5 & 12 & 4 & 0 & 2 & 2 \\
\hline Total $(A-B)$ & 34 & 35 & 61 & 36 & 0 & 10 & 47 & 7 & 17 & 23 & -3 & 1 & 15 & 73 & 4 \\
\hline Total acumulado & 34 & 69 & 130 & 166 & 166 & 176 & 223 & 230 & 247 & 270 & 267 & 268 & 283 & 356 & 360 \\
\hline
\end{tabular}

Fonte: Livro de sócios da CAEX - organização do autor.

Ao final do ano 2000, constata-se um avanço significativo no cumprimento da meta de crescimento do quadro social, chegando-se a um número de 360 sócios (Tabela 1): um aumento de cerca de 959 \% em relação aos 34 fundadores. Esse incremento ilustra bem o aumento do poder sociopolítico experimentado pela Cooperativa no nível municipal 
e microrregional. Além disso, a sua projeção junto ao movimento pela defesa da Amazônia garantiu também um fortalecimento político a nível nacional e internacional.

No entanto, a ampliação do poder político da CAEX não foi ancorada numa consolidação econômica de mesmo porte. Ao contrário, o desempenho econômico da entidade foi bastante débil (Gráfico 1). Esse fraco desempenho econômico tem gerado algumas crises financeiras significativas. Com isso, têm sido prejudicadas tanto a sua sustentabilidade enquanto empresa econômica, como a sua capacidade de cumprir seus principais objetivos, econômicos e sociais, relacionados à melhoria duradoura da qualidade de vida dos seus cooperados. A sobrevivência da Cooperativa, assim, fica dependendo de projetos externos e de doações que garantam recursos para cobrir seus prejuízos operacionais.

\section{Gráfico 1 - Sobras e perdas acumuladas pela CAEX ao longo do período 1990-2000.}

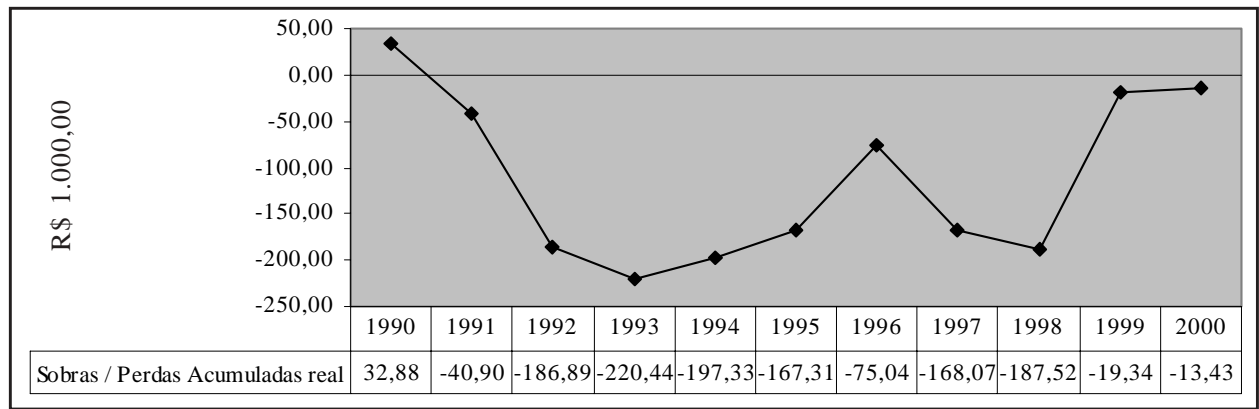

Fonte: Balanços Patrimoniais da CAEX - anos 1990 a 2000.

Obs.: Valores em R\$ corrigidos para o ano 2000 - média do ano (IGP/FGV base ago. 94).

A dificuldade de consolidação econômica da CAEX não tem passado despercebida pelos envolvidos na sua construção, seja pelo seu conjunto de cooperados, seja pelos diferentes apoiadores externos, principalmente aqueles que de alguma forma compõem a chamada aliança pela defesa da floresta amazônica. No entanto, a diversidade de explicações e, conseqüentemente, de soluções apontadas para essa situação específica da CAEX também reflete os diferentes matizes existentes nessa articulação. A maior ou menor capacidade de influência dos diferentes agentes sociais envolvidos tem levado à predominância de visões específicas sobre os problemas e soluções que, mesmo não sendo consensuais, têm conseguido impor-se às demais, influindo decisivamente nas estratégias adotadas pela Cooperativa. 
Grosso modo, duas visões têm norteado a análise dos problemas econômicos da CAEX e a busca de soluções decorrentes. Uma, que apresenta um forte viés economicista, concentra suas explicações em algum tipo de restrição de fatores de produção, sejam eles capital, máquinas e equipamentos ou matéria-prima. Como conseqüência desse tipo de análise, as soluções visualizadas enfocam a busca permanente de financiamentos e de doações externas que permitam à Cooperativa aumentar seu capital, comprar máquinas e equipamentos e ampliar seu estoque de matéria-prima.

A análise dos balanços patrimoniais da CAEX mostra um grau elevado de implantação dessa estratégia, uma vez que o patrimônio líquido da Cooperativa tem apresentado cifras bem mais significativas que o montante de capital realizado pelos sócios (Tabela 2). No entanto, essa elevação do patrimônio, obtida por meio de doações, não tem garantido a consolidação econômica esperada. Ao contrário, constata-se que, mesmo tendo construído e equipado suas Usinas de Castanha e de Borracha e conseguido, em vários anos, grandes volumes de matéria-prima e outros insumos para a produção, graças à doação de capital de giro, a CAEX não conseguiu resolver sua situação financeira.

Tabela 2 - Composição do capital da CAEX entre os anos 1990 e 2000.

\begin{tabular}{|l|c|c|c|c|c|}
\hline & $\begin{array}{c}\text { Patrimônio } \\
\text { Líquido }\end{array}$ & $\begin{array}{c}\text { Capital } \\
\text { Realizado }\end{array}$ & $\begin{array}{c}\text { Capital } \\
\text { Real/PL } \\
\%\end{array}$ & $\begin{array}{c}\text { Doações } \\
\%\end{array}$ & $\begin{array}{c}\text { Doações } \\
\text { / PL } \\
\%\end{array}$ \\
\hline 1990 & $497.854,72$ & $25.052,11$ & 5,03 & $298.567,60$ & 59,97 \\
\hline 1991 & $760.710,36$ & $31.505,59$ & 4,14 & $631.597,59$ & 83,03 \\
\hline 1992 & $801.229,48$ & $70.132,48$ & 8,75 & $643.733,06$ & 80,34 \\
\hline 1993 & $3.367 .569,48$ & $155.471,37$ & 4,62 & $3.432 .538,63$ & 101,93 \\
\hline 1994 & $1.857 .876,02$ & $36.975,33$ & 1,99 & $2.018 .231,08$ & 108,63 \\
\hline 1995 & $1.238 .899,81$ & $26.343,46$ & 2,13 & $1.379 .861,70$ & 111,38 \\
\hline 1996 & $965.938,95$ & $36.258,09$ & 3,75 & $1.004 .719,15$ & 104,01 \\
\hline 1997 & $791.918,54$ & $37.148,29$ & 4,69 & $922.841,14$ & 116,53 \\
\hline 1998 & $618.308,50$ & $36.173,97$ & 5,85 & $769.650,77$ & 124,48 \\
\hline 1999 & $761.762,26$ & $21.508,05$ & 2,82 & $759.597,35$ & 99,72 \\
\hline 2000 & $553.422,83$ & $30.000,00$ & 5,42 & $536.851,88$ & 97,01 \\
\hline
\end{tabular}

Fonte: Balanços Patrimoniais da CAEX. Obs: valores em R\$ corrigidos para o ano $2000-$ média do ano (IGP-FGV base ago. 94). 
Tal constatação tem fortalecido uma segunda explicação para os problemas econômicos da Cooperativa, essa de cunho gerencialista, que admite não terem os problemas decorrido da restrição de fatores de produção, mas de uma incapacidade de gerenciamento da produção e da comercialização. Mais comumente, esse tipo de análise concentra sua crítica no setor gerencial da Cooperativa propriamente dito. As principais soluções apontadas para esse problema têm se concentrado na realização de cursos de gerenciamento para diretores e administradores da CAEX e na constante substituição da equipe gerencial, buscando-se a contratação de pessoal com melhores qualificações profissionais. Os resultados dessas ações têm ficado aquém das expectativas, e mais recentemente tem prevalecido a proposição de se limitar a responsabilidade gerencial dos próprios cooperados, levando-se a uma tutela externa da administração da Cooperativa.

O exemplo mais marcante dessa perspectiva pode ser visto em um convênio de cooperação técnica estabelecido entre o Governo do Estado do Acre e a CAEX, firmado em setembro de 1999, com o principal objetivo de modernizar e fortalecer a gestão empresarial da Cooperativa. O convênio estabeleceu como competências do Governo do Estado a elaboração do plano de assistência técnica para a modernização da gestão cooperativa, a nomeação de uma comissão técnica para executar e monitorar o plano e o pagamento de uma nova equipe administrativa, substituindo a anterior. As medidas seriam executadas pela Secretaria Executiva de Florestas e Extrativismo (SEFE). À CAEX coube, basicamente, acatar as sugestões da comissão técnica, implementar as atividades previstas e manter uma sistemática de informações para o monitoramento do convênio (cf. Governo do Estado do Acre, 1999). Nota-se, nesse convênio, uma tendência de subordinação da Cooperativa à equipe técnica do Governo.

Uma limitação dos dois tipos de explicação mencionados consiste no fato de focarem isoladamente aspectos específicos da Cooperativa, sejam os fatores de produção, seja a equipe gerencial, desconectando-os do todo. Dessa maneira, apenas alcançam explicações estáticas e parciais, de onde surgem soluções pouco efetivas. Uma firma, segundo o enfoque neo-schumpeteriano explicitado por Baptista (1997: 1243), deve ser pensada tanto pelos recursos materiais que possui - bens físicos, financeiros e pessoal - como pelos recursos imateriais (ou intangíveis) - principalmente conhecimento e tecnologia - e também pela forma como esses recursos são organizados e coordenados pela unidade decisória.

Esse enfoque neo-schumpeteriano tem sido adotado por algumas das vertentes econômicas atuais que se propõem a uma abordagem 
dinâmica das firmas. Esse é o caso das 'teorias econômicas evolucionárias' que nortearam este trabalho. De acordo com Dosi G Nelson (1994) as 'teorias evolucionárias' propõem-se a examinar seu objeto de estudo a partir do movimento no tempo, envolvendo tanto os elementos aleatórios que geram ou renovam variações, como os mecanismos sistemáticos de seleção das variações.

Nessa perspectiva, o estudo do movimento das firmas parte dos aspectos internos, que envolvem seus recursos materiais e imateriais, bem como as formas de organização e coordenação desses recursos. No entanto, deve-se observar que esses aspectos internos se relacionam também externamente à firma, com outras firmas, com o mercado e com o Estado. A gestão da firma, portanto, consiste na coordenação da sua atuação frente a esse conjunto complexo de relações, significando ainda a tomada de decisões estratégicas que garantam seu desempenho positivo no longo prazo. Dessa forma, a capacidade de gestão é também um fator de competitividade fundamental.

Este estudo analisou os problemas econômicos da CAEX tendo em vista suas origens no complexo de relações sócio-econômicas presentes no universo da Cooperativa e na forma como ela organiza a sua produção. Para tanto, duas premissas tiveram que ser elencadas. Primeiramente, que a CAEX não é uma instituição homogênea, desempenhando atividades consensualmente definidas. Ao contrário, a Cooperativa caracteriza-se por ser um conjunto de relações entre indivíduos e grupos heterogêneos, com aspirações e perspectivas diferentes e até contraditórias, que disputam e geram tensões no seu interior. Esse conjunto de relações tampouco pode ser entendido apenas como as relações internas ao ambiente da Cooperativa, mas também como as relações no ambiente externo, tanto em nível local, como nacional e mundial.

Em segundo lugar, a situação econômica da CAEX não é estática e atemporal. Em cada momento distinto de sua história, há tendências predominantes que refletem as correlações de força capazes de impor decisões e perspectivas. Cada decisão tomada reflete-se nesse momento em si, mas também, está conectada às decisões anteriores e cria conseqüências para os momentos futuros.

Por isso, partiu-se do estudo da trajetória da CAEX, que permite compreender sua situação atual como decorrência de sua história, diminuindo os riscos de análises estáticas e homogeneizadoras. A trajetória de cada firma é específica, construída a partir das possibilidades e decisões tomadas a cada instante, em função de suas relações internas e externas. Essas decisões não são necessariamente as melhores possíveis, mas aquelas que se impuseram às demais alternativas, percebidas 
ou não, pelos tomadores de decisão. Com isso, criam-se processos cumulativos de aprendizados e também de erros, o que faz com que as decisões tomadas num determinado momento influenciem os momentos seguintes.

\section{O setor agroindustrial da CAEX}

A Cooperativa Agroextrativista de Xapuri possui atualmente duas usinas de beneficiamento de produtos extrativistas, uma de castanha e outra de borracha. Ambas funcionam na sede do município e são administradas por uma equipe composta pela administração central da Cooperativa e por uma gerência específica para cada Usina. As Usinas articulam-se com os cooperados por intermédio dos núcleos da cooperativa nos seringais, que compram parte da matéria-prima. No caso da castanha, também se articulam por intermédio das microusinas de beneficiamento que funcionam nos seringais. Neste estudo, a análise restringir-se-á à Usina de Beneficiamento de Castanha.

Essa Usina começou a operar em 1990. Em 1991 sofreu uma reforma para ampliação e aquisição de maquinários, configurando-se a partir de então o sistema de produção que vigorou até o final do período estudado (dezembro de 2000). Seu fluxo operacional inicia-se com o armazenamento da castanha in natura num armazém de madeira interligado à sua planta. No armazém, a castanha deve ser constantemente revirada para facilitar a secagem e evitar que se deteriore.

O primeiro passo para se iniciar o processamento propriamente dito é a secagem e a limpeza da castanha, que fica por algumas horas numa estufa rotativa, aquecida por combustão de lenha e pela própria casca da castanha beneficiada em períodos anteriores. Nessa estufa, a castanha vai aquecendo-se e a amêndoa, internamente, desprende-se da casca. Da estufa, as castanhas caem por gravidade num tanque de água, onde ficam imersas para o amolecimento da casca. Desse tanque, as castanhas vão para o descasque.

O descasque é manual, realizado principalmente por mulheres, que utilizam aparelhos rústicos, semelhantes a quebra-nozes. As próprias descascadoras fazem a primeira seleção das amêndoas, em função do seu nível de integridade e tamanho. Da mesa de descasque, as amêndoas vão para outras estufas, também aquecidas por combustão de lenha e casca de castanha, para a secagem até o nível de umidade adequado.

Das estufas, as amêndoas já secas passam por outras etapas de seleção e classificação. Após a seleção final, vão para o empacotamento. A CAEX embala a castanha em pacotes a vácuo de 20 kg, no padrão do 
mercado internacional. A partir de 1995, introduziu pacotes a vácuo de 250 g, apropriados para a comercialização direta com os consumidores finais.

Os pacotes de $250 \mathrm{~g}$, segundo relatório de uma entidade de assessoria - CAPINA -, permitem uma elevação na receita da Usina e na sua rentabilidade (CAPINA, 1995). Contudo, esse tipo de embalagem não assumiu uma importância muito significativa na produção da CAEX. Problemas burocráticos para a obtenção de registros legais das embalagens, dificuldades em ajustar a estrutura física da Usina para incluir o empacotamento de $250 \mathrm{~g}$ na linha de produção regular e o desconhecimento de estruturas de comercialização voltadas para esse tipo de produto fizeram com que os pacotes de $250 \mathrm{~g}$ tivessem um papel secundário e irregular ao longo dos anos.

Os objetivos principais das duas Usinas para a CAEX são agregar valor à produção extrativista dos seus cooperados e eliminar intermediários na cadeia de produção, comercializando o produto beneficiado diretamente com mercados consumidores. A meta central dessa estratégia é conseguir elevar a renda dos cooperados e melhorar seu padrão de vida. No entanto, para que essa estratégia funcione de maneira eficiente, é necessária uma participação efetiva dessas Usinas no mercado, alcançada em função de sua competitividade em relação aos concorrentes.

Analisando a formação de competitividade em complexos de produção agroindustrial vinculados à agricultura familiar, Campos (1995: 5-6) identifica três fatores determinantes: a formação de uma reserva de mercado; a produtividade do setor da transformação agroindustrial e a produtividade do setor fornecedor de insumos. O fracasso em algum desses três aspectos pode inviabilizar a formação do complexo agroindustrial, seja pela ausência de um mercado consumidor para seus produtos, seja pela incapacidade de competir com seus concorrentes num mercado existente. Portanto, a análise detalhada de cada um desses aspectos indica mais claramente as perspectivas e limitações de um complexo agroindustrial em formação.

No caso da CAEX, esses aspectos assumem formas específicas, cuja análise desnuda, em melhor medida, as dificuldades que a Cooperativa enfrenta no seu processo de consolidação. Ao mesmo tempo, o estudo de como a CAEX vem se posicionando em relação a cada um permite aferir o grau de competitividade que já foi alcançado.

No que diz respeito à formação de uma reserva de mercado, esta deve ser entendida não apenas como a existência de demanda para as mercadorias produzidas, mas também como uma relação consolidada entre a firma e determinado mercado, que permita à primeira estabele- 
cer vantagens em relação aos seus concorrentes. Um conceito-chave para essa discussão são as chamadas 'barreiras à entrada', ou seja, a capacidade de determinadas firmas de criarem impedimentos, inclusive ligados à manipulação de seus preços e margens de lucro, que dificultem a entrada de novos concorrentes no mercado (Possas, 1985).

Observando-se as relações comerciais estabelecidas pela CAEX para a castanha beneficiada, nota-se que não se construiu uma reserva de mercado de forma eficiente. Apesar de diversas relações comerciais pontuais em mercados solidários, ecológicos e também em mercados regulares, em nível tanto local, como nacional e internacional, a Cooperativa não conseguiu inserir-se num mercado específico que consolidasse uma posição vantajosa em relação aos seus concorrentes. Houve alguns períodos de relações comerciais relativamente estáveis, principalmente com a Cultural Survival (EUA), a Nutrimental (BR) e a CTM (Itália), mas nenhuma se manteve por muitos anos e a troca de parceiros comerciais foi constante.

No caso da CAEX, fica claro que o problema da não-formação de uma reserva de mercado não pode ser relacionado à inexistência de demanda para seu produto. Na realidade, esse problema tem ligação com a sua incapacidade de conseguir apresentar um grau de regularidade na produção e na comercialização. As freqüentes interrupções no funcionamento das Usinas e, conseqüentemente, na disponibilidade de produtos para comercialização geram essas irregularidades e impedem a consolidação de relações comerciais mais duradouras. Portanto, os problemas comerciais da Cooperativa são muito mais reflexo de suas limitações produtivas do que o contrário. É no setor produtivo, portanto, que se deve concentrar a análise.

\section{Produtividade do setor agroindustrial}

De maneira geral, a capacidade das empresas de assumirem posições de vanguarda em relação aos seus concorrentes costuma ser vista como resultado das chamadas vantagens de escala. Apesar da importância dessas vantagens de escala, elas não podem ser consideradas as únicas vantagens competitivas existentes. Outras vantagens podem ser construídas, mesmo em situações de produção abaixo das escalas ótimas de produção, ou seja, abaixo da escala maximizadora. Essas vantagens são denominadas por Possas (1985) de vantagens de diferenciação de produtos, ou seja, vantagens em função de certas especificações, desempenho e qualidade, design e aspectos ergonômicos, comercialização, linhas de produto e assistência técnica.

No caso da Usina de Beneficiamento de Castanha da CAEX, notase a elevada importância dada à questão da escala de produção, en- 
tendida como o principal fator de criação de competitividade e consolidação de uma reserva de mercado. Uma referência significativa na definição dessa estratégia agroindustrial foi a análise de James LeFleur, economista da ONG ECOTEC (Sociedade para o Desenvolvimento Tecno-Ecológico), que participou da formulação e da execução de um projeto de apoio à CAEX, financiado pela Fundação Ford, IAF (Inter American Foundation) e WWF (World Wildlife Fund). Segundo este, o mercado interno brasileiro consome apenas 5\% da castanha produzida e a solução para o setor é buscar ampliar a participação no mercado internacional (LaFleur, 1993 citado por Bryon, [s.d.]: 27). Bryon ([s.d.], por seu turno, demonstra que essa porcentagem fica entre 500 a 900 toneladas de castanha descascada por ano.

Uma observação atenta mostra que a estratégia desenhada pela ECOTEC e adotada pela CAEX demonstra-se falha, já que a produção anual da Cooperativa, no seu melhor ano, ficou em 134,3 toneladas e, na média de todos os anos, em 58, 27 toneladas (ver Tabela 3 - p 15). Assim, para a CAEX em si, o mercado interno brasileiro nunca foi insignificante, sem contar que é mais flexível e favorável para um aprendizado operacional. Apesar disso, a Cooperativa priorizou a exportação para o mercado internacional, principalmente por intermédio de uma entidade americana com inserção no comércio ecológico - a Cultural Survival.

A decisão da Cooperativa de já iniciar a atividade comercializando no mercado internacional levou-a a ter que planejar a produção a partir de quantidades compatíveis com as escalas exigidas nesse nível de comércio. Estas, dados os custos de transporte, a demanda dos compradores internacionais e os custos transacionais de exportação, são maiores que na comercialização no mercado interno. Assim, a orientação predominante em toda a trajetória da CAEX foi a busca da ampliação das escalas de operação das Usinas para aumentar a competitividade da sua produção agroindustrial.

A dimensão das Usinas é um indicador interessante para se analisar até que ponto a Cooperativa conseguiu aumentar sua competitividade por meio dessa estratégia de ganhos de escala. É importante verificar em que medida os desempenhos verificados ao longo dos anos corresponderam à dimensão calculada para as Usinas. Para tanto, foram levantados os custos de produção da Usina de Castanha e seu respectivo ponto de equilíbrio. Dessa maneira fica mais clara a comparação entre as dimensões produtivas planejadas e as efetivamente alcançadas.

O levantamento dos custos foi realizado a partir de informações obtidas com a equipe gerencial da CAEX, em dezembro de 2000. A Cooperativa desenvolve quatro tipos de atividades: castanha, borracha, 
comércio de mercadorias e projetos. No caso dos custos com o pessoal do escritório central referentes a diversas atividades, levou-se em consideração a distribuição do tempo de trabalho dedicado a cada atividade para compor os respectivos custos. Assim, chegou-se à estimativa de que a equipe administrativa gasta $50 \%$ do seu tempo com a castanha. Outras despesas de escritório, como água, luz e telefone, foram divididas igualmente (25\%) pelas atividades. Os custos com infra-estrutura de transporte também foram divididos igualmente, porém, como envolvem uma atividade a mais - aluguel para terceiros - ficaram distribuídos em $20 \%$ para cada atividade produtiva.

Como a CAEX não possui um sistema contábil que permita um registro preciso dos custos e despesas e das receitas operacionais das Usinas, muitos dos valores utilizados são estimados. Mesmo assim, eles fornecem uma idéia aproximada que satisfaz suficientemente os objetivos deste trabalho.

Quadro 1 - Custos da Usina de Beneficiamento de Castanha da CAEX, em Reais (R\$) para dezembro do ano 2000.

\begin{tabular}{|l|l|r|}
\hline CUSTO FIXO & DESCRIÇÃO & R\$ \\
\hline & Despesa Anual & 130,00 \\
\hline Impostos & IPTU & 200,00 \\
\hline & Alvará & 90,00 \\
\hline & Ibama & 360,00 \\
\hline Taxas Mínimas & Água & 360,00 \\
\hline & Luz & 300,00 \\
\hline & Telefone & $8.262,72$ \\
\hline Pessoal da Usina & 2 vigias & $9.639,84$ \\
\hline & 1 gerente & $4.800,00$ \\
\hline Transporte (caminhão+trator) & manutenção + combustíveis & $2.478,82$ \\
\hline (20\% do tempo) & 2 motoristas & $2.754,24$ \\
\hline Área Administrativa & 1 Secretária & $3.624,00$ \\
\hline (50\% do tempo) & 1 Presidente & $12.600,00$ \\
\hline & 1 Gerente Geral & $8.400,00$ \\
\hline & 1 Gerente Contábil & $4.200,00$ \\
\hline & 1 Técnico Administrativo & 180,00 \\
\hline Despesas Escritório & Água & 450,00 \\
\hline (25\% do total) & Luz & $1.800,00$ \\
\hline & Telefone & \\
\hline IPTU & 32,50 & 50,00 \\
\hline & alvará de funcionamento & \\
\hline
\end{tabular}


Continuação

\begin{tabular}{|c|c|c|}
\hline CUSTO FIXO & DESCRIÇÃO & $\mathbf{R} \$$ \\
\hline & Material de escritório & 900,00 \\
\hline Total (exclui depreciação) & $61.612,12$ & \\
\hline \multicolumn{3}{|l|}{ CUSTOS VARIÁVEIS } \\
\hline Lenha & $2 \mathrm{~m} 3 / \mathrm{dia}^{*} 22$ dias $^{*} 10$ meses & $3.520,00$ \\
\hline LuZ & & $7.200,00$ \\
\hline Telefone & & $1.250,00$ \\
\hline Manutenção & & $2.000,00$ \\
\hline \multirow[t]{3}{*}{ Pessoal } & 2 foguistas & $6.885,60$ \\
\hline & 1 pesador & $3.442,80$ \\
\hline & 1 empacotador & $3.442,80$ \\
\hline Equipe de Apoio & 2 classificadores & $6.885,60$ \\
\hline \multirow[t]{2}{*}{ (para cada 56 descascadoras) } & 3 catadores & $10.328,40$ \\
\hline & 2 limpadores / embaladores & $6.885,60$ \\
\hline Descascadoras & 56 descascadoras & $123.457,60$ \\
\hline Matéria-Prima & 56 descascadoras & \\
\hline \multirow{3}{*}{ (prevê $10 \%$ de perda) } & 4,45 latas / descascador / dia & $263.155,20$ \\
\hline & caixas $20 \mathrm{Kg} 20 \mathrm{~kg}(1,25 \mathrm{a}$ unidade $)$ & $9.702,00$ \\
\hline & sacos aluminizados (0,90 a unid.) & $6.985,44$ \\
\hline Custo Variável Total & & $455.141,04$ \\
\hline \multicolumn{3}{|l|}{ Receita } \\
\hline \multirow[t]{5}{*}{ Produção } & 56 descascadoras & \\
\hline & 1 lata $=3 \mathrm{Kg} \mathrm{kg}$ castanha final & $147.840,00$ \\
\hline & $1^{\mathrm{a}}$ qualidade & $88.704,00$ \\
\hline & $2^{\mathrm{a}}$ qualidade & $22.176,00$ \\
\hline & $3^{\mathrm{a}}$ qualidade & $36.960,00$ \\
\hline Receita Bruta & 56 descascadoras & \\
\hline \multirow[t]{3}{*}{$A$} & Preço preço em Xapuri (1a a qual. $)=4,80$ & $425.779,20$ \\
\hline & Preço em Xapuri (2a ${ }^{\mathrm{a}}$ qual. $)=4,00$ & $88.704,00$ \\
\hline & Preço em Xapuri (3a $a^{a}$ qual. $)=3,00$ & $110.880,00$ \\
\hline ICMS: (- $20 \%$ do total) $\times 12 \%$ & Castanha de $1^{\text {a }}$ qualidade & $40.874,80$ \\
\hline \multirow[t]{2}{*}{$\mathrm{B}$} & Castanha de 2 ${ }^{\mathrm{a}}$ qualidade & $8.515,58$ \\
\hline & Castanha de $3^{\text {a }}$ qualidade & $10.644,48$ \\
\hline Receita Líquida & Castanha de $1^{\text {a }}$ qualidade & $384.904,40$ \\
\hline \multirow[t]{2}{*}{$A-B$} & Castanha de $2^{\mathrm{a}}$ qualidade & $80.188,42$ \\
\hline & Castanha de $3^{\text {a }}$ qualidade & $100.235,52$ \\
\hline Receita Líquida & Total & $565.328,33$ \\
\hline \multicolumn{3}{|l|}{ Ponto de Equilíbrio } \\
\hline \multicolumn{3}{|l|}{ (excluída depreciação) } \\
\hline Custo Fixo fixo (CF) & & $61.612,12$ \\
\hline Receita Líquida. Final & & $565.328,33$ \\
\hline Custo Variável Total & & $455.141,04$ \\
\hline Margem Bruta (MB) & Receita Líq. - Custo Variável & $110.187,29$ \\
\hline Produção. Anual (Kg) & & 147.840 \\
\hline Pte. Equil. (Kg prod.) & $\mathrm{CF} /(\mathrm{MB} / \mathrm{Kg})$ & 82.666 \\
\hline Pte. Equil. (latas) & & 30.311 \\
\hline
\end{tabular}

Fonte: Entrevistas com equipe gerencial da CAEX e Usina de Castanha. 
O ponto de equilíbrio corresponde à quantidade de produção em que a receita se iguala aos custos totais. Portanto, espera-se que qualquer atividade produtiva bem-sucedida seja superior ao ponto de equilíbrio. O cálculo do ponto de equilíbrio foi feito conforme Muenchen (1992), a partir da seguinte equação:

$$
\begin{aligned}
& \text { P.Eq. = CF / ( MB / Prod. ) onde, } \\
& \text { P.Eq. = ponto de equilíbrio } \mathrm{MB}=\text { margem bruta } \\
& \mathrm{CF}=\text { custo fixo anual Prod. }=\text { quantidade produzida }
\end{aligned}
$$

No caso da Usina de Beneficiamento de Castanha, os cálculos realizados neste trabalho tiveram como base apenas a produção de embalagens de $20 \mathrm{~kg}$. Não foram incluídas as embalagens de $250 \mathrm{~g}$ em função da irregularidade observada na sua produção. Em relação às microusinas, os custos de produção não foram considerados, mesmo sendo diferentes dos da Usina central. Nas microusinas, a castanha é descascada e secada e vai para a Usina central na fase de seleção final e empacotamento. Posteriormente, ela é comercializada juntamente com a produção da central. A participação das microusinas no processo produtivo foi bastante irregular ao longo dos anos. Para efeito de nossos cálculos, foram consideradas todas as castanhas comercializadas como sendo beneficiadas na Usina central.

Outra observação relevante sobre o ponto de equilíbrio da Usina de Beneficiamento de Castanha é que este não pode ser visto de forma estática e imutável. Variações nos preços das matérias-primas, dos insumos, dos salários e dos produtos finais geram modificações em toda a estrutura de custos da Usina. Outros tipos de variações importantes são relativos às perdas de armazenagem, que aqui foram consideradas em torno de 10\% (apesar de haver estimativas de até 40\% em anos anteriores), à produtividade do trabalho e ao pagamento ou não de encargos sociais, à quantidade de trabalhadores contratados e ao rendimento da matéria-prima. Por isso, o ideal seria trabalhar com cálculos ex-post, ajustados anualmente, porém a falta de registros confiáveis acerca da produção da Usina não permitiu a utilização de tais cálculos. Os dados utilizados são estimativas.

Observando-se o Quadro 1, constata-se que o ponto de equilíbrio da Usina de Beneficiamento de Castanha da CAEX, excluída a depreciação, é estimado em $82.666 \mathrm{~kg}$ de castanha beneficiada produzida, ou 30.311 latas de matéria-prima (6.062,2 hectolitros). A exclusão da depreciação da infra-estrutura justifica-se pelo fato de a CAEX ter apresentado uma elevada capacidade de conseguir doações para a construção de infra-estrutura, o que torna possível a contínua busca desses 
recursos quando necessário. É claro que, numa perspectiva de consolidação a longo prazo, a atividade produtiva deveria possibilitar também a reposição da depreciação da infra-estrutura. Neste trabalho adotouse esse quadro mais favorável para a CAEX, ou seja, com reposição da infra-estrutura depreciada por meio de doações por mais alguns anos.

A produção mínima necessária para a Usina de Castanha equilibrar sua receita e despesas é de $82.666 \mathrm{~kg}$ de castanha beneficiada. Mesmo considerando as variações ao longo dos anos, neste trabalho será considerado esse valor como constante para todos os anos, desde 1992. Ressalva-se que, de acordo com vários documentos, até 1993, os custos de produção da Usina de Castanha eram bem mais elevados, sendo adotada a partir de 1993 uma série de medidas voltada para a redução desses custos. Essas medidas incluíram desde a redução nas perdas de compra e armazenagem até a terceirização do trabalho das descascadoras (a chamada 'descentralização' urbana).

Comparando-se o ponto de equilíbrio da Usina de Beneficiamento de Castanha com a produção efetivamente realizada (Tabela 3), nota-se que a Usina vem trabalhando quase sempre abaixo do ponto de equilíbrio, ou seja, com perdas. Mesmo nos anos em que ela trabalhou acima do ponto de equilíbrio estimado - 1992 e 1993 -, há indícios de que seus custos de produção na época eram bem mais elevados do que no ano de 2000, o que deslocaria seu ponto de equilíbrio para cima, minimizando ou até invertendo essa situação. Portanto, pode-se concluir que a Usina de Beneficiamento de Castanha da CAEX, da forma como foi montada, tem sistematicamente gerado perdas para a Cooperativa.

Tabela 3 - Produção anual da Usina de Beneficiamento de Castanha da CAEX no período 1992-2000.

\begin{tabular}{|l|c|r|r|r|}
\hline Ano & $\begin{array}{c}\text { Ponto de Equilíbrio } \\
\text { (Kg amêendoa) }\end{array}$ & $\begin{array}{c}\text { Amêndoas } \\
\text { (Kgkg) }\end{array}$ & $\begin{array}{c}\text { Matéria - Prima } \\
\text { (latas) }\end{array}$ & $\begin{array}{c}\text { Rendimento } \\
\text { (Kg amêndoa } \\
\text { (lata) }\end{array}$ \\
\hline 1992 & 82.666 & 134.300 & $\mathrm{~s} / \mathrm{r}$ & - \\
\hline 1993 & 82.666 & 114.500 & $\mathrm{~s} / \mathrm{r}$ & - \\
\hline 1994 & 82.666 & 76.060 & 28.208 & 2,70 \\
\hline 1995 & 82.666 & 52.378 & 16.879 & 3,10 \\
\hline 1996 & 82.666 & 67.969 & 21.275 & 3,19 \\
\hline 1997 & 82.666 & 0 & 0 & - \\
\hline 1998 & 82.666 & 19.920 & 5.694 & 3,50 \\
\hline 1999 & 82.666 & 17.500 & 5.500 & 3,18 \\
\hline 2000 & 82.666 & 41.811 & 17.250 & 2,42 \\
\hline Média & - & 58.271 & 13.544 & 3,02 \\
\hline
\end{tabular}

Fonte: Relatórios Anuais da Cooperativa Agroextrativista de Xapuri-diversos anos. 
Essa situação mostra que a dimensão da Usina de Castanha, principalmente depois de sua ampliação em 1991, quando passou a buscar ganhos de escala, mostrou-se incompatível com as possibilidades operacionais e organizativas da Cooperativa. A CAEX não conseguiu sustentar um nível de produção compatível com a infra-estrutura montada. Em função disso, a Usina tem trabalhado abaixo do seu ponto de equilíbrio, ou seja, tem acumulado perdas.

A estratégia de implementação da unidade agroindustrial de castanha não conseguiu, portanto, assegurar à Cooperativa as vantagens de escala esperadas. Ao contrário, a estratégia adotada gerou desvantagens, ou seja, perdas decorrentes do fato de a operação realizada manter-se abaixo do ponto de equilíbrio. Dessa maneira, a CAEX não conseguiu consolidar vantagens em relação aos seus concorrentes e ainda teve que lidar com perdas financeiras que freqüentemente levaram a interrupções na produção, que contribuíram para a não formação de relações comerciais mais sólidas.

Esses aspectos quantitativos da produção não podem ser vistos de maneira desvinculada de outras questões de caráter mais qualitativo. A questão tecnológica, por exemplo, é um fator determinante da produtividade no setor da transformação agroindustrial. Essa questão envolve tanto os aspectos específicos da agroindústria, como o ambiente tecnológico de um modo geral.

A questão tecnológica, do ponto de vista interno das agroindústrias cooperativas da Amazônia, traz algumas especificidades. Lambert (1998) faz uma separação interessante entre hard tech e soft tech. A hard tech está relacionada ao conjunto de máquinas e equipamentos, enquanto a soft tech representa os processos de administração e gerenciamento. Considerar as questões administrativas e gerenciais como parte integrante da tecnologia de uma empresa é realmente oportuno e permite que se visualizem melhor alguns problemas e desafios enfrentados pelas cooperativas agroindustriais amazônicas.

Numa agroindústria, as hard e soft tech têm que ser desenvolvidas de maneira articulada. No entanto, Lambert (1998) aponta como problema recorrente na região o fato de os projetos agroindustriais das cooperativas atribuírem maior prioridade às hard tech do que às soft tech. Enquanto as máquinas e equipamentos são vistos como o principal fator de eficiência das agroindústrias, pouca atenção é dada aos processos administrativos e gerenciais.

Apesar dos problemas com a falta de conhecimento e de adaptabilidade local das máquinas e equipamentos, a hard tech não tem sido 
fator impeditivo da implementação dos projetos agroindustriais. Apesar do custo relativamente elevado para o nível de capitalização das cooperativas, estas têm conseguido financiamentos e doações que garantem a compra de equipamentos e máquinas existentes em outras regiões do país. O próprio caso das duas Usinas da CAEX, ambas implantadas a partir de doações, é um bom exemplo.

No entanto, para as agroindústrias cooperativas da região, mais difícil do que adquirir máquinas e equipamentos, tem sido consolidar processos de organização e administração que permitam que essas máquinas e equipamentos funcionem a contento. Isso mostra que o acesso a máquinas e equipamentos não garante, necessariamente, uma alta produtividade do setor agro-industrial. Mesmo tendo equipamentos bem adaptados à região e ao produto em questão, uma agroindústria precisa desenvolver processos de administração e de gerenciamento eficientes. Caso contrário, não é possível articular-se o conjunto de fatores necessários à operacionalização da produção em níveis de competitividade elevados.

No entanto, os processos de administração e de gerenciamento não podem ser vistos como uma atribuição e responsabilidade única e exclusiva da equipe administrativa e da direção da empresa. Numa firma, vista como uma instituição complexa, a capacidade competitiva está associada diretamente à sua organização interna, o que permite uma combinação eficiente de todos os fatores envolvidos na produção. Portanto, não se trata de processos decisórios individuais, mas de um processo dinâmico de formação de competências coletivas e cumulativas.

Assim, a produtividade passa por uma combinação do hard tech com o soft tech, como acima descritos. As possibilidades nesse sentido estão condicionadas pelo que Cimoli e Dosi (1992) definem como capacidade tecnológica da firma. Esse conceito traduz a idéia de uma capacidade adquirida pela firma para lidar, de forma dinâmica, com a tecnologia disponível no ambiente externo, apropriando-se dela, adaptando-a e inovando-a a partir do seu ambiente interno.

A capacidade tecnológica de uma firma, portanto, não é um conceito estático. Ao contrário, deve ser entendido a partir de trajetórias tecnológicas específicas de cada empresa, expressando um caráter evolutivo a partir de seus processos de aprendizagem e pesquisa seletiva (Cimoli G Dosi, 1992). Por isso, uma firma, mesmo podendo comprar máquinas e equipamentos no mercado, não pode comprar 'capacidade tecnológica', pois esta está diretamente relacionada aos processos de aprendizagem e pesquisa internos e específicos de cada empresa.

A capacidade tecnológica de uma firma tem um caráter cumulati- 
vo. Cimoli e Dosi (1992) definem cumulatividade como a incorporação ao longo do tempo de capacidades de resolução de problemas, de possibilidades de pesquisa, de conhecimentos sobre produtos e equipamentos. Por isso, mesmo quando estão num mesmo ambiente tecnológico e possuem os mesmos tipos de infra-estrutura tecnológica, é um erro considerar diferentes empresas como portadoras da mesma capacidade tecnológica.

Apesar dos aspectos internos e específicos das empresas no que se refere ao desenvolvimento da capacidade tecnológica, esta não pode ser vista como fator exclusivamente endógeno. Existe uma importante interação entre o ambiente tecnológico mais geral e os comportamentos e as formas de organização das firmas. Dosi e Nelson (1994) ressaltam que é justamente nessa interação que se processam os mecanismos de seleção de tecnologias. As categorias utilizadas para a apreensão dessas interações entre o campo tecnológico e os padrões organizacionais são as rotinas organizacionais e as competências.

As rotinas de uma firma, segundo Dosi e Malerba (1986), possuem uma dupla natureza. São orientadas para a resolução de problemas, ou seja, são análogas a normas de produção num sistema cognitivo complexo. Ao mesmo tempo, as rotinas significam mecanismos de gestão e controle. A esse respeito, os autores apontam que é necessário um balanço entre centralização-descentralização no processo organizativo, permitindo o fortalecimento de rotinas sem que essas se tornem tão rígidas que impeçam a adaptação e a inovação.

Dosi e Nelson (1994) identificam três tipos distintos de rotinas de uma firma. A primeira é composta pelos procedimentos operacionais standard, que determinam no dia-a-dia o que e quanto a firma produz. O segundo tipo de rotina refere-se ao comportamento de investimentos, definindo como a firma faz seus investimentos de longo prazo, o que se reflete no seu crescimento ou declínio. O terceiro é a rotina de busca de inovações e melhorias, que se dá não apenas por ações fortuitas e aleatórias, mas também por processos deliberados e sistemáticos de procura.

As competências, por sua vez, correspondem à capacidade interna de criar rotinas orientadas à resolução de problemas, de acessar e aplicar conhecimentos externos, de dominar tecnologias e produção e de compreender as demandas dos consumidores. Nesse sentido, as competências têm três características básicas: são implícitas, específicas e complexas (Dosi G Malerba, 1986). Assim, só podem ser específicas de cada firma, desenvolvidas mediante processos próprios de aprendizagem.

A respeito dos processos de aprendizagem, enfatiza-se que estes 
são dependentes das trajetórias das firmas (path-dependents), uma vez que são locais e cumulativos. Isso significa que as competências das firmas são dadas no presente em função da sua trajetória de aprendizagem, pelas tecnologias preexistentes, pelos seus valores e prejulgamentos (Dosi G Nelson, 1994). Além disso, os processos de aprendizagem envolvem sempre processos de adaptação imperfeita que fazem com que se acumulem também erros. Por isso não existem garantias de que uma determinada rotina de uma firma seja ótima, mesmo quando essa firma é mais eficiente que suas concorrentes, o que deixa sempre um espaço para surgirem inovações.

Um aspecto interessante relacionado às rotinas e trajetórias de aprendizado no desenvolvimento de competências específicas são os procedimentos chamados de Triplo C. Humphrey e Schmitz (1996) os definem como procedimentos (i) orientados para os consumidores, (ii) coletivos e (iii) cumulativos. Essa tripla orientação permite que as empresas fortaleçam tanto sua dinamização interna, como as interações positivas com outras empresas e instituições no ambiente socioeconômico externo.

A orientação para os consumidores fortalece a competitividade, pois permite o desenvolvimento de habilidades que correspondam às necessidades específicas desses consumidores. O caráter coletivo permite potencializar a cooperação entre firmas para a criação de processos de aprendizagem mútuos, inclusive no campo tecnológico. A percepção de que os processos são cumulativos permite que as empresas criem mecanismos de valorização da estabilidade interna.

No caso do setor agroindustrial da CAEX, nota-se que a preocupação central esteve ligada à ampliação da escala a partir do investimento em infra-estrutura física, máquinas e equipamentos. Porém, mesmo com as dificuldades inerentes às limitações do ambiente tecnológico amazônico, a Cooperativa conseguiu avanços nessa estratégia. Contudo, não conseguiu bons resultados econômicos em função de não ter consolidado rotinas organizacionais e competências que garantissem uma maior competitividade.

A irregularidade da sua produção gerou fragilidades na comercialização e impediu o estabelecimento de relações comerciais mais constantes com o mesmo consumidor. No caso da castanha, isso impossibilitou que a CAEX consolidasse um processo de aprendizado voltado para o atendimento de demandas concretas. Sua incapacidade de criar interações positivas com seus consumidores, por longo tempo, fez com que não se consolidasse uma trajetória de aprendizagem específica, e poucas inovações foram incorporadas ao processo de beneficiamento da 
castanha.

Quanto à cumulatividade, nota-se, ao longo da história da CAEX, uma troca muito freqüente de ocupantes de cargos-chave, tanto diretivos, como administrativos. Essa grande rotatividade de pessoas ocupando cargos-chave na CAEX normalmente implica mudanças de procedimentos e de táticas e dificulta a consolidação de rotinas organizacionais. Além disso, com a constante troca de funcionários, inibe-se um processo de aprendizagem cumulativa mais efetivo, uma vez que muitos conhecimentos são tácitos, ou seja, são conhecimentos adquiridos pela pessoa ou grupo de pessoas por meio de sua experiência própria e da prática cotidiana. O aprendizado fica acumulado não na infra-estrutura física, mas nas pessoas individualmente e nas rotinas organizativas da empresa. A troca constante de pessoal, portanto, leva a perdas do conhecimento individual acumulado e à não consolidação de rotinas organizacionais sólidas.

A partir dos elementos observados, pode-se concluir que a CAEX não conseguiu grandes avanços na sua capacidade tecnológica, apesar dos financiamentos e doações para a compra de máquinas e equipamentos e para a construção de sua infra-estrutura. Isso principalmente em função do pequeno desenvolvimento da capacidade de criar rotinas e competências que assegurassem uma trajetória tecnológica, organizacional e de aprendizado dinâmica e eficiente. Por isso, a CAEX não conseguiu, ao longo do tempo, melhorias significativas na sua produtividade agroindustrial que pudessem alterar a estrutura de custos de suas Usinas e reverter o quadro de perdas operacionais.

\section{O setor fornecedor de insumos}

O terceiro fator levantado por Campos (1995), considerado por ele o ponto crítico, é a produtividade do setor fornecedor de insumos agroindustriais, no caso da CAEX, o setor agroextrativista. Uma das principais dificuldades que logo se vislumbra ao analisar esse fator reside na percepção de que os insumos, que representam os maiores custos de produção da agroindústria, são o principal componente da renda dos produtores. Há, portanto, um antagonismo entre a agroindústria, que visa reduzir custos diminuindo os preços dos insumos, e os produtores, que desejam aumentar sua renda elevando os preços dos seus produtos.

Nos casos estudados por Campos (1995), esse antagonismo leva a agroindústria a impor um processo de seleção de fornecedores, comprando apenas daqueles capazes de reduzir seus custos e de ampliar a escala de produção. Isso se dá por meio da incorporação de novas tecnologias em escalas ótimas visando o aumento da produtividade. Aqueles que não conseguem atingir esses resultados simplesmente deixam 
de fornecer para a agroindústria.

Numa cooperativa, a solução aplicada não deve reproduzir essa mesma lógica meramente econômica, uma vez que se trata não de uma relação entre agroindústria e fornecedores, mas de uma relação mais orgânica do tipo cooperativa/cooperados. A construção de uma solução mais adequada deve levar em consideração tanto a dimensão econômica, como a dimensão social das cooperativas (Schneider, 1984). Afinal, uma cooperativa é ao mesmo tempo empresa econômica e associação de pessoas e deve equilibrar essas duas dimensões, caso contrário, tende a se descaracterizar.

Assim, se a Cooperativa privilegia apenas os aspectos econômicos e toma medidas como uma agroindústria qualquer, por exemplo, forçando os preços para baixo e eliminando os fornecedores em piores condições, ela entra em contradição com sua dimensão social. Persistindo nessa direção, ela tende a abandonar sua condição de Cooperativa, se não formalmente, pelo menos na prática, e transforma-se numa empresa não-cooperativa. Assim, vai restringindo cada vez mais a livre associação e a participação democrática dos cooperados na sua gestão e impondo decisões a partir de uma lógica exclusivamente economicista.

A situação inversa também é negativa. Se a Cooperativa prioriza apenas sua dimensão social e não enfrenta seus problemas econômicos, ela tende a fracassar enquanto empresa, falindo ou tornando-se um instrumento inadequado para a conquista dos benefícios almejados. Por exemplo, simplesmente nivelar os preços dos insumos industriais produzidos pelos cooperados nos patamares mais altos, sem tomar nenhuma medida para corrigir essas distorções, é um sério erro do ponto de vista econômico.

A análise das Usinas da CAEX indica a existência desse tipo de problema. Já em 1994, num relatório de avaliação externa da Usina de Castanha (cf. IPHAE, 1994: Avaliação do Processamento da Castanha-do-Pará na Cooperativa Agroextrativista de Xapuri), o fornecimento de matéria-prima, em relação tanto ao preço pago aos produtores, como ao controle de qualidade do produto, era indicado como um dos principais responsáveis pelos elevados custos de produção. Principalmente quando comparados com os praticados pelas usinas de castanha da Bolívia, que começavam a assumir papel importante no mercado internacional.

Essa estratégia resulta em dois problemas centrais. O primeiro refere-se à perda de liquidez no curto prazo, uma vez que a Cooperativa tem que imobilizar grande parte do seu capital nos estoques de castanha. O segundo diz respeito à rentabilidade, já que os altos preços pagos elevam sobremaneira os custos de produção, o que, na maioria dos 
anos, tem significado perdas operacionais para a Cooperativa.

De forma resumida, pode-se dizer que a CAEX encontra-se num círculo vicioso em que uma série de decisões estratégicas tomadas em uma estrutura de gestão centralizada tem privilegiado aspectos de aumento da escala de produção agroindustrial que, por sua vez, têm se mostrado incompatíveis com a capacidade organizacional real da Cooperativa como um todo e com as capacidades produtivas dos associados fornecedores de matéria-prima. Isso levou a CAEX a privilegiar o aumento do número de associados e a comprar matéria-prima de nãosócios, tendo que pagar preços altos e atrativos pela castanha bruta, elevando ainda mais seus custos de produção. Isso acarretou prejuízos operacionais constantes, reduzindo paulatinamente a capacidade produtiva da Cooperativa e afastando-a ainda mais da escala planejada.

Os problemas na produção geraram instabilidades não apenas financeiras, mas também políticas junto aos cooperados. Para contornar essa situação, a CAEX tem priorizado medidas imediatistas de garantia de benefícios aos cooperados, como, por exemplo, preços elevados pagos pela matéria-prima, agravando a situação financeira no médio-pra-

zo. Essa situação só tem se sustentado graças a um eficiente esquema de captação de recursos externos.

A captação de recursos externos, no entanto, tem se favorecido e dependido da força política de algumas lideranças na negociação de projetos e financiamentos. Assim, tem se reforçado a centralização da gestão em torno dessas lideranças que se tornam imprescindíveis para a manutenção do atual esquema econômico de sobrevivência. Ao mesmo tempo, afasta-se cada vez mais a participação dos cooperados nos processos de planejamento e tomada de decisões da empresa, o que tende a reforçar a adoção de medidas que, na prática, mostram-se incompatíveis com as características organizacionais e produtivas desses mesmos cooperados.

\section{Conclusão}

A discussão levantada sobre os elementos internos da competitividade da Cooperativa Agroextrativista de Xapuri revela um quadro negativo. Embora existam possibilidades de formação de reservas de mercado, sobretudo perseguindo vantagens de diferenciação de produtos, estas não têm sido exploradas eficientemente na sua trajetória. A produção agroindustrial pouco evoluiu, apesar do acesso a máquinas e equipamentos (hard tech). A relação com os fornecedores de matériasprimas tem se sustentado em cima de condições atrativas no curto prazo (preços altos pagos aos produtores), porém prejudiciais numa pers- 
pectiva de longo prazo (perdas operacionais).

Dessa forma, considerando-se os elementos indicados e a necessidade de articulá-los para o estabelecimento de competências próprias da Cooperativa, conclui-se que o principal gargalo na trajetória da CAEX está relacionado às suas rotinas organizacionais. As rotinas organizacionais são fundamentais para articular os diversos elementos internos de competitividade, na relação tanto com o mercado, quanto com o setor agroindustrial e com os cooperados.

O conceito de rotinas encerra duas idéias fundamentais: organização interna e gestão. No caso da CAEX, ambos os aspectos envolvem uma discussão sobre o papel dos associados nos aspectos produtivos e decisórios da Cooperativa. Segundo Lauschner (1995), a compreensão do papel dos cooperados na viabilização de uma agroindústria cooperativa deve basear-se nos seguintes aspectos fundamentais: a eficiência empresarial em função da eficácia, ou seja, em função dos associados, e a verdadeira participação do associado na gestão da empresa. Portanto, a eficiência e a eficácia assentadas numa verdadeira participação dos cooperados na gestão da Cooperativa são a base de uma rotina organizacional ideal para a CAEX.

A participação dos cooperados na gestão da Cooperativa, no entanto, só é possível se a própria organização da Cooperativa for compatível com a capacidade organizativa dos cooperados. Um problema recorrente mostrado por Santos de Moraes (1986: 20-22) em experiências de empresas rurais de produção cooperativista é a existência de incompatibilidades estruturais entre a organização da empresa e a capacidade organizativa dos próprios cooperados. Frente a essa incompatibilidade estrutural, a participação dos cooperados na vida da Cooperativa não consegue avançar para a criação das rotinas organizacionais necessárias para que a empresa desenvolva uma trajetória de aprendizado eficaz e estabeleça suas competências específicas.

Portanto, o principal problema da atual forma de gestão da CAEX reside na inexistência de um diálogo pleno entre os responsáveis pela administração - diretoria e corpo administrativo - e o conjunto dos cooperados. Dessa maneira, prevalecem as decisões tomadas pela direção, que muitas vezes mostram-se incompatíveis com as possibilidades e aspirações dos cooperados nos seringais. Assim, as metas traçadas dificilmente são alcançadas, o que compromete a viabilidade da empresa cooperativa.

Uma forma de gestão mais adequada para a Cooperativa deveria privilegiar o diálogo entre todos os envolvidos. Esse diálogo, em que todos se reconheçam como sujeitos históricos, ou seja, pessoas detento- 
ras de uma história de saber e de fazer, de viver e de transformar o mundo em que vivem, é base para a construção de um processo de participação e organização consentidas (Carvalho, 1994: 8). Sem isso, não se formam os processos de motivação e mobilização desejáveis.

Discutindo o caminho complexo de construção dessa participação e organização consentidas, Carvalho (1994) aponta a necessidade de compartilhamento entre todos os envolvidos nos processos decisórios, desde a concepção até a implantação, embasados em análises elaboradas da realidade. Mesmo assim, o autor adverte que não se pode perder de vista que, nos momentos de implantação dos projetos, há uma tendência de destacar apenas a preocupação limitada às demandas imediatas, abandonando-se a análise de suas causas mais profundas. Por isso, o processo de construção da participação e organização consentidas deve ter como princípio uma reflexão-ação permanente e compartilhada que permita a constante rearrumação dos planos de ação (Carvalho, 1994: 29).

No caso da CAEX, a centralização do processo decisório da entidade tem inibido o envolvimento dos cooperados na busca de soluções e na implementação de um programa para a resolução dos problemas da Cooperativa. Com isso, criou-se um descompasso entre as características e demandas planejadas para as unidades de produção agroindustrial e as características organizativas concretas da produção e do modo de vida dos cooperados - os seringueiros. Qualquer possibilidade de consolidação da CAEX, no entanto, passa pela compatibilização entre as rotinas organizativas da empresa econômica e as características organizativas dos seus cooperados. 


\section{Referências bibliográficas}

ACRE. Documento de Convênio entre o Governo do Estado do Acre e a Cooperativa Agroextrativista de Xapuri estabelecido em 16/09/ 1999. Mimeografado.

BAPTISTA, Margarida O Enfoque Neo-Schumpeteriano da Firma. In: Anais do XXV Encontro Nacional de Economia. Vol 2. ANPEC. Recife, PE. 1997. 1236 - 1254 p.

BRYON, Eliane. Mercado da castanha do Pará. In: Manual de processamento descentralizado da castanha-do-pará. Ecotec. [s. d.]. p. 21-30.

CAEX. Ata da reunião do Conselho de Administração em 04.10.1989. Livro de Atas da CAEX. Mimeografado.

. Relatório de Administração Geral da CAEX - gestão 1989/1990. 1991. Mimeografado.

. Livro de Sócios da CAEX - período 1988 a 2000. Mimeografado.

. Relatório Anual da Usina de Castanha da CAEX do Ano de 1995. 1996. Mimeografado.

CAMPOS, Índio. Complexos de produção agroindustrial e mecanismos de formação de preços na agricultura. Belém: NAEA/UFPA, 1995, 17 p. (Paper $\left.\mathrm{n}^{\circ} 46\right)$.

CAPINA. Estudo de retomada financeira da CAEX. 1995. Mimeografado.

CARVALHO, Horácio Martins de. A participação e a organização consentidas como uma das dimensões da cidadania. Relatório de Consultoria - IICA/BIRD - Projeto Áridas. Curitiba, 1994. Mimeografado. $92 \mathrm{p}$.

CIMOLE, Mario; DOSI, Giovanni. Tecnologia y desarrollo: algunas consideraciones sobre los recientes avances en la economía de la innovación. In: URANGA, Mikel Gomez et al. (comp.). El Cambio Tecnologico Hacia el Nuevo Milenio. Icaria, 1992. p. 21-64.

COSTA, Francisco de A. Ecologismo e questão agrária na Amazônia. Belém: NAEA/UFPA, 1992. 81 p. (Série Estudos SEPEQ, 1). 
DOSI, Giovanni; MALERBA, Franco. Organizational Learning and Institucional Embeddedness: an introduction to the diverse evolutionary paths of modern corporations. In: DOSI, Giovanni; MALERBA (eds). Franco Organization and Strategy in the Evolution of Enterprise. London: Mc Millan, 1986. p. 1-17.

DOSI, Giovanni; NELSON, Richard R. An Introduction to Evolucionary Theories in Economics. Journal of Evolutionary Economics, $\mathrm{n}^{\circ} 4$, p. 153-172, 1994.

HUMPHREY, John; SCHMITZ, Hubert. The Triple C Approach to Local Industrial Policy. World Development, v. 24, nº 12, p. 1859-1877, 1996.

LAMBERT, Alain. O uso dos recursos não-lenhosos da floresta: perspectivas na Amazônia. Elementos de uma estratégia para um desenvolvimento econômico sustentável. Poema tropic, nº 2, p. 24-30, jul./dez. 1998.

LAUSCHNER, Roque. Agribusiness, cooperativa e produtor rural. São Leopoldo: Editora Unisinos, 1995. 296 p.

MUENCHEN, José V. Análise econômica e financeira de associações. Rio de Janeiro: AS-PTA/IRED, 1992. 34 p.

POSSAS, Mário L. Estruturas de mercado em oligopólio. São Paulo: Ed. Hucitec, 1985.

SANTOS DE MORAES, Clodomir. Elementos sobre a teoria da organização no campo. Movimento dos Trabalhadores Rurais Sem Terra. São Paulo, 1986. 62 p.

SCHNEIDER, José Odelso. Uma proposta para o balanço social das cooperativas. Perspectiva Econômica, ano XIX, nº 45, p. 67-90, 1984. (Série Cooperativismo $\mathrm{n}^{\circ} 14$ ).

STR de XAPURI. Projeto de desenvolvimento cooperativista. 1989. Mimeografado.

STR de XAPURI; CNS; CUT. Chico Mendes. São Paulo: Gráfica e Editora FG, 1989. 35 p. 